\title{
ESTIMATIVA DO VOLUME DE FLUIDO EPITELIAL PULMONAR RECUPERADO NO LAVADO BRONCOALVEOLAR NO EQUINO
}

\author{
Katia Moreira Silva, ${ }^{1}$ Carlos Frederico Marques Guimarães, ${ }^{2}$ Lara Medeiros Blasquez Olmedo, ${ }^{3}$ \\ Estevão Grossi Aguiar Silva, ${ }^{4}$ Nayro Xavier Alencar ${ }^{5}$ e Daniel Augusto Barroso Lessa ${ }^{6}$ \\ 1. Pós-graduanda em clínica e reprodução da UFF. E-mail: katitinhabr@yahoo.com.br \\ 2. Químico, MSc, Departamento de Controle Químico de POA, Universidade Federal Fluminense \\ 3. Médica veterinária, Universidade Federal Fluminense \\ 4. Médico veterinário, MSc, Exército Brasileiro \\ 5. Doutor, professor adjunto III, Patologia Clínica Veterinária, Universidade Federal Fluminense \\ 6. Doutor, professor adjunto III, Cínica Médica de Grandes Animais, Universidade Federal Fluminense.
}

\section{RESUMO}

O lavado broncoalveolar (LBA) é uma técnica que permite coletar o fluido epitelial pulmonar (FEP) e avaliar a integridade do trato respiratório posterior. A instilação de solução isotônica para a sua realização resulta numa diluição significativa do FEP. A ureia é comumente utilizada como marcador de diluição, em virtude do seu livre trânsito pelas membranas biológicas. Contudo, a metodologia previamente estabelecida que faz uso dela é de difícil reprodução, principalmente pela utilização de reagentes e equipamentos de difícil obtenção. O objetivo deste trabalho foi descrever uma metodologia para este cálculo utilizando um kit comercial de determinação de ureia (ureia UV LabTest ${ }^{\circledR}$ ). Foram obtidas amostras pareadas de sangue e de lavado broncoalveolar de dezoito equinos adultos. A partir de concentrações conhecidas de ureia no LBA de equinos, foi estabelecida uma equação de regressão linear e sua curva-padrão, utilizadas para cálculo das concentrações nas amostras de LBA. $\mathrm{O}$ volume estimado de FEP teve média de $0,52 \pm 0,12 \mathrm{~mL}$. O percentual médio obtido de FEP em relação ao volume recuperado de LBA foi de $0,39 \pm 0,08 \%$. Estes resultados estão compatíveis com os descritos, provando que a metodologia desenvolvida permitiu obter resultados confiáveis, podendo ser empregada para estimar o volume de FEP e, consequentemente, calcular a concentração ou atividade de componentes desejados.

PALAVRAS-CHAVES: Equinos, fluido epitelial pulmonar, lavado broncoalveolar, ureia.

\section{ABSTRACT}

\section{ESTIMATION OF VOLUME OF EPITHELIAL LINING FLUID RECOVERED BY BRONCHOALVEOLAR LAVAGE IN EQUINE}

Bronchoalveolar lavage (BAL) is a widespread technique that allows collection of pulmonary epithelial lining fluid (PELF) and evaluation of integrity of the lower airways. The instillation of isotonic solution needed for collection results in significant dilution of the PELF. Due to its ability to freely cross biologic membranes urea is commonly used as a marker of PELF dilution. Nevertheless, the previously established methodology is difficult to be reproduced, especially since it utilizes reagents and equipments that are difficult to obtain. The objective of this study was to describe a methodology for measuring urea utilizing a commercial kit (Ureia UVLabTest $\left.{ }^{\circledR}\right)$.
Paired samples of blood and BALF were obtained from 18 adult horses. A standard curve of known urea dilutions in equine BALF provided a linear regression equation that allowed calculation of unknown urea concentrations in BALF samples. The mean estimated PELF volume was $0.52 \pm 0.12 \mathrm{~mL}$. The mean PELF percentage in relation to recovery BALF was $0.39 \pm 0.08 \%$. These results are compatible with the ones previously described, demonstrating that the methodology presented here produced reliable results and can be utilized to estimate the PELF volume and consequently calculate concentration or activity of components or substances of interest.

KEY WORDS: Bronchoalveolar lavage, horses, pulmonary epithelial lining fluid, urea. 


\section{INTRODUÇÃO}

Nas vias aéreas posteriores, o fluido epitelial pulmonar (FEP) forma uma interface entre o trato respiratório subjacente e o meio ambiente externo (DARGAVILLE et al., 1999). Esse fluido contém elementos celulares e moleculares como, por exemplo, enzimas e imunoglobulinas, os quais podem ser utilizados para a avaliação da integridade do trato.

O lavado broncoalveolar (LBA) é um meio de diagnóstico e de estudo dos mecanismos de inflamação em uma variedade de doenças. Esta técnica permite coletar o FEP e avaliar seus componentes. Para a realização desse procedimento na espécie equina, é recomendada a infusão de 200 a $500 \mathrm{~mL}$ de fluido isotônico (ROBINSON, 2001). Embora o volume introduzido possa ser padronizado, o volume recuperado não pode ser controlado, em virtude das diferenças de colapso pulmonar e drenagem (HASLAM \& BAUGHMAN, 1999), o que resulta numa diferença nos volumes recuperados que variam de $40 \%$ a $60 \%$ do infundido (ROBINSON, 2001). Portanto, o volume de FEP obtido por meio desse procedimento é variável e apresenta-se intensamente diluído.

Diferenças consideráveis têm sido relatadas em contagens totais de células e concentrações de marcadores bioquímicos, por causa da recuperação variável de FEP. Dessa forma, a comparação quantitativa dos componentes em diferentes amostras pode não ser válida, pois as concentrações desses componentes no LBA dependem não somente das suas concentrações no fluido epitelial pulmonar, mas também da proporção de fluido epitelial pulmonar em cada amostra de lavado broncoalveolar obtida (MILLS \& LITSTER, 2006).

Desde que RENNARD et al. (1986) estabeleceram uma técnica utilizando a ureia como marcador endógeno de diluição para estimar o FEP obtido, esta tem sido amplamente utilizada em diversas espécies como suínos (HENNIG-PAUKA et al., 2001), equinos (MC GORUM et al., 1993), felinos (MILLS \& LITSTER, 2006) e caninos (MILLS \& LITSTER, 2005). A albumina também pode ser empregada (MC GORUM et al., 1993), assim como marcadores exógenos como azul de metileno (BAUGHMAN et al., 1983), inulina (KIRSCHVINK et al., 2001) e marcadores radioativos (EFFROS et al., 1992; WARD et al., 1992).
A ureia é utilizada como marcador de diluição, em virtude de seu baixo peso molecular, o que possibilita o seu livre trânsito pelas membranas biológicas, estando em equilíbrio no plasma e no fluido epitelial pulmonar (ADAMS et al., 1963; STRANG et al., 1968 apud RENNARD et al., 1986). Considerando, então, a concentração deste composto nitrogenado no plasma equivalente à concentração no FEP, é possível estimar o volume de FEP recuperado a partir da obtenção desses valores.

Em equinos, até o momento, as técnicas utilizadas para estimar o FEP (Mc GORUM et al., 1993; KIRSCHVINK et al., 2001; FERNANDES et al., 2003) baseiam-se em adaptações da técnica estabelecida por RENNARD et al. (1986). Porém, em decorrência das alterações realizadas na metodologia com relação aos volumes de reagente e amostra, aliados a kits de difícil obtenção no Brasil ou necessidade de equipamentos que utilizam reagentes bioquímicos específicos e de alto custo, há dificuldades de aplicação das metodologias.

O objetivo deste trabalho foi estabelecer e descrever detalhadamente uma metodologia para estimar o volume de FEP obtido por meio de LBA utilizando-se um kit comercial de determinação de ureia disponível no Brasil, mais acessível para utilização em equipamentos de baixo custo e de fácil execução.

\section{MATERIAL E MÉTODOS}

Utilizaram-se dezoito equinos, sendo onze machos e sete fêmeas com idade variando entre 3 a 21 anos, pertencentes ao Regimento de Cavalaria de Guarda Andrade Neves EB/ME/RJ. Os animais foram mantidos semiestabulados em baias de aproximadamente $9 \mathrm{~m}^{2}$, sem cama, alimentados com $5-6 \mathrm{~kg}$ de ração comercial com $12 \%$ de proteína bruta (PB)/ animal e 2-3kg de feno de Coast Cross/animal, escovados diariamente e soltos entre quatro e seis vezes por semana. Os equinos trabalhavam diariamente em atividades esportivas ou de patrulha, sendo vermifugados trimestralmente e vacinados contra influenza, tétano, encefalomielite leste e oeste, raiva, garrotilho e leptospirose.

Para a determinação da concentração de ureia sérica, $10 \mathrm{~mL}$ de sangue foram obtidos por venopunção jugular, em tubos de colheita a vácuo, estéreis e sem 
anticoagulante $\left(\right.$ Vacutainer $\left.^{\mathbb{B}}\right)$, imediatamente antes da sedação. O soro foi separado por centrifugação a 220 $g$ por cinco minutos (Fanem ${ }^{\circledR}$ 206R).

Para a obtenção dos lavados broncoalveolares, os animais foram sedados com cloridrato de xilazina a $10 \%\left(\mathrm{SEDAZINE}^{\circledR}\right)$ na dosagem de $0,5-1,0 \mathrm{mg} / \mathrm{kg}$, IV e contidos com aziar. Introduziu-se uma sonda de silicone (Equine Broncho-alveolar Lavage Catheter, BIVONA $^{\circledR}$ ) ao mesmo tempo que o trato respiratório era anestesiado com cloridrato de lidocaína (LIDO$\mathrm{VET}^{\circledR}$ ) a $0,5 \%$. O LBA era obtido por meio da infusão e imediata aspiração de $250 \mathrm{~mL}$ de solução salina $0,9 \%$ aquecida a $37^{\circ} \mathrm{C}$. As amostras foram mantidas refrigeradas até o momento do processamento, e consideradas adequadas quando o volume recuperado era no mínimo $40 \%$ do infundido (ROBINSON, 2001). Submeteramse os lavados à centrifugação $800 \mathrm{~g}$ por cinco minutos a $4^{\circ} \mathrm{C}$ (centrífuga refrigerada $\mathrm{HERMLE}^{\circledR}$ ), sendo o sobrenadante separado para a dosagem da ureia.

As dosagens de ureia sérica foram realizadas em duplicata por espectrofotometria (BIOPLUS 2000 ${ }^{\circledR}$ ), utilizando-se um kit bioquímico comercial padronizado (ureia UV LabTest ${ }^{\mathbb{}}$ ).

Para a determinação da concentração da ureia no LBA, foi utilizado o mesmo kit citado anteriormente. Tendo em vista a baixa concentração de ureia encontrada em lavados broncoalveolares de equinos (McGORUM et al., 1993), foi necessário estabelecer uma equação de regressão linear e uma curva-padrão.

A partir de concentrações previamente conhecidas deste composto nitrogenado no LBA de equinos (MCGORUM et al., 1993) e utilizando-se o padrão fornecido pelo fabricante do kit, diluições seriadas foram preparadas em concentrações crescentes de 0,08 a $0,16 \mathrm{mg} / \mathrm{dL}$ com intervalos de 0,02 . Os padrões de ureia assim diluídos foram utilizados como amostra, adicionando-se o reagente nas proporções indicadas pelo fabricante. Em seguida, colocados em cubeta de $10 \mathrm{~mm}$ e posteriormente submetidos à análise espectrofotométrica (MICRONAL B280 ${ }^{\circledR}$ ), com leitura em comprimento de onda $(\lambda=340 \mathrm{~nm})$. Com a determinação dos valores de absorbância estabeleceram-se a equação de regressão linear e a curva-padrão (Figura 1).

Os sobrenadantes das amostras do LBA foram então analisados de forma semelhante por espectrofotometria nas mesmas condições dos padrões de ureia, sendo necessário incluir um blank do sobrenadante sem reagentes para corrigir a absorbância da amostra.

Para determinar o total de ureia presente no volume de LBA recuperado multiplica-se a concentração de ureia no sobrenadante do LBA pelo volume recuperado. Ureia total do lavado recuperado = concentração de ureia no LBA X volume recuperado.

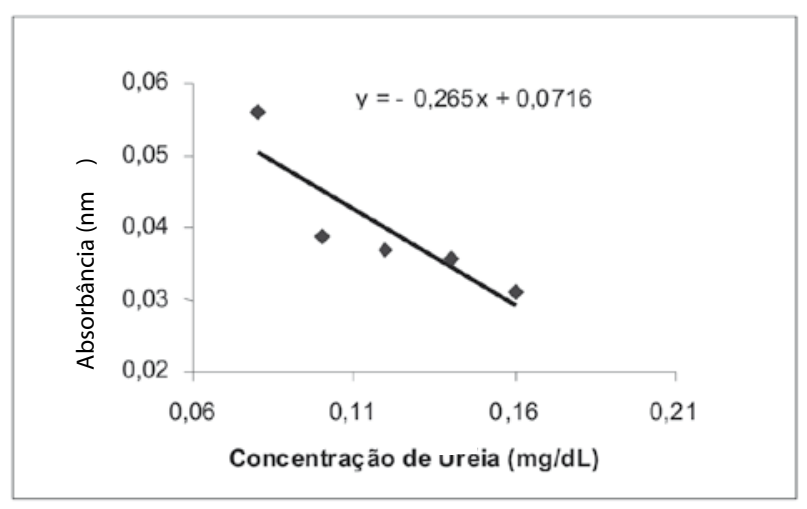

FIGURA 1. Representação gráfica da curva-padrão e da equação de regressão linear obtidas a partir das medidas de absorbância de concentrações de ureia conhecidas.

O volume estimado de FEP obtido (volume total estimado de FEP presente no fluido coletado) foi obtido dividindo-se a quantidade total de ureia no fluido do lavado broncoalveolar pela concentração de ureia no soro (RENNARD et al., 1986). Volume estimado de FEP $(\mathrm{mL})=$ ureia total no lavado recuperado/concentração ureia sérica.

\section{RESULTADOS E DISCUSSÃO}

O volume recuperado correspondeu em média a $54,0 \pm 8,7 \%$ do volume infundido. Esses valores estão de acordo com a faixa de variação de $40 \%$ a $60 \%$ descrita por ROBINSON et al. (2001) e também próximos aos valores obtidos por RENNARD et al. (1986).

$\mathrm{Na}$ Tabela 1 estão apresentados os resultados referentes à concentração de ureia no lavado $(\mathrm{mg} /$ $\mathrm{dL})$, ao volume absoluto $(\mathrm{mL})$ recuperado de lavado, à concentração total de ureia no lavado $(\mathrm{mg})$ e à concentração de ureia sérica $(\mathrm{mg} / \mathrm{dL})$.

O valor médio de concentração de ureia do lavado foi de $0,14 \pm 0,2 \mathrm{mg} / \mathrm{dl}$, número compatível com os previamente descritos por MC GORUM et al. (1993), 
ainda que tenham sido utilizados kits diferentes. Isto permite concluir que a equação de regressão linear obtida permite obter resultados confiáveis.

$\mathrm{Na}$ Tabela 2, estão relacionados o volume estimado de FEP obtido $(\mathrm{mL})$ e a porcentagem de FEP presente no volume de lavado recuperado.

Com base nos resultados obtidos, a média do volume estimado de fluido epitelial pulmonar recuperado neste estudo foi de $0,52 \pm 0,12 \mathrm{~mL}$. O percentual médio estimado de FEP presente no lavado está de acordo com os obtidos por Mc GORUM et al. (1993) em equinos, alcançando uma média de $0,4 \%(0,1-1,0 \%)$, o que também ratifica a técnica aqui estabelecida. RENNARD et al. (1986) obtiveram porcentagem superior, com média de $1,0 \pm 0,1 \%$ do fluido infundido em humanos e volume médio de 1,7 $\pm 0,2 \mathrm{~mL}$ de FEP. Essas diferenças estão diretamente relacionadas ao volume infundido, uma vez que, quanto maior o volume infundido, maior o volume recuperado e maior a abrangência de área pulmonar atingida. Considerando as diferentes proporções anatômicas pulmonares entre humanos e equinos, o volume utilizado por RENNARD et al. (1986) foi proporcionalmente maior do que o utilizado neste trabalho.

Alguns autores relatam limitações referentes à precisão da técnica do cálculo do FEP tomando por base a ureia como marcador de diluição. Estudos demonstram que a alta pressão hidrostática e a distorção local do pulmão que ocorrem durante a realização do lavado bronco alveolar levam à abertura de "poros" no epitélio que permitem a passagem de água e outros solutos (WARD et al., 1992). Logo, este componente pode se difundir livremente e de forma passiva do interstício pulmonar para o líquido infundido durante a realização do procedimento (RENNARD et al., 1986). Dessa forma, o LBA pode conter ureia derivada não só do fluido epitelial, mas também do interstício. Esta última fração pode levar a um cálculo de volume de FEP superestimado (KIRSCHVINK et al., 2001). A magnitude desse fenômeno é proporcional ao tempo em que o líquido infundido permanece em contato com o tecido pulmonar (RENNARD et al., 1986). MARCY et al. (1987) demonstraram em estudo com pacientes humanos que há difusão em quantidade significativa de ureia durante a realização do LBA. WARD et al.
(1992) verificaram que um tempo superior a dois minutos pode permitir alterações nos níveis de ureia no espaço alveolar.

Apesar dessas limitações, esse marcador de diluição ainda é empregado uma vez que, com uma única instilação e aspiração imediata, é sabido que um mínimo de $80 \%$ da ureia recuperada é derivada da ureia realmente presente no FEP (RENNARD et al., 1986).

TABELA 1. Valores individuais, médias e desvios-padrão para as concentrações de ureia no LBA, volume recuperado de LBA, ureia total do LBA recuperado e concentração sérica de ureia. Rio de Janeiro, 2007

\begin{tabular}{|c|c|c|c|}
\hline Animal & $\begin{array}{l}\text { Ureia lavado } \\
(\mathrm{mg} / 100 \mathrm{~mL})\end{array}$ & $\begin{array}{l}\text { Volume } \\
\text { recuperado de } \\
\text { LBA }(\mathrm{mL})\end{array}$ & $\begin{array}{c}\text { Ureia total do } \\
\text { LBA recuperado } \\
\text { (mg) }\end{array}$ \\
\hline 1 & 0,14 & 110 & 0,15 \\
\hline 2 & 0,15 & 128 & 0,19 \\
\hline 3 & 0,16 & 134 & 0,22 \\
\hline 4 & 0,15 & 124 & 0,19 \\
\hline 5 & 0,15 & 168 & 0,25 \\
\hline 6 & 0,13 & 165 & 0,22 \\
\hline 7 & 0,16 & 110 & 0,18 \\
\hline 8 & 0,12 & 128 & 0,15 \\
\hline 9 & 0,15 & 115 & 0,17 \\
\hline 10 & 0,12 & 110 & 0,13 \\
\hline 11 & 0,15 & 172 & 0,25 \\
\hline 12 & 0,15 & 112 & 0,17 \\
\hline 13 & 0,17 & 140 & 0,24 \\
\hline 14 & 0,15 & 160 & 0,24 \\
\hline 15 & 0,12 & 118 & 0,14 \\
\hline 16 & 0,14 & 130 & 0,18 \\
\hline 17 & 0,09 & 148 & 0,13 \\
\hline 18 & 0,13 & 160 & 0,20 \\
\hline $\begin{array}{c}\text { Médias } \pm \\
\text { DP }\end{array}$ & $0,14 \pm 0,02$ & $135,1 \pm 21,80$ & $0,19 \pm 0,04$ \\
\hline
\end{tabular}


TABELA 2. Valores individuais, médias e desvios-padrão para o volume de fluido epitelial pulmonar estimado obtido e percentual deste fluido com relação ao volume de LBA recuperado. Rio de Janeiro, 2007

\begin{tabular}{ccc}
\hline Animal & Volume FEP $(\mathrm{mL})$ & $\begin{array}{c}\text { \% FEP no lavado } \\
\text { recuperado }\end{array}$ \\
\hline 1 & 0,45 & 0,41 \\
2 & 0,46 & 0,36 \\
3 & 0,56 & 0,42 \\
4 & 0,44 & 0,36 \\
5 & 0,63 & 0,37 \\
6 & 0,71 & 0,43 \\
7 & 0,59 & 0,53 \\
8 & 0,44 & 0,35 \\
9 & 0,28 & 0,24 \\
10 & 0,60 & 0,54 \\
11 & 0,71 & 0,41 \\
12 & 0,53 & 0,48 \\
13 & 0,59 & 0,42 \\
14 & 0,52 & 0,32 \\
15 & 0,34 & 0,29 \\
16 & 0,53 & 0,41 \\
17 & 0,39 & 0,26 \\
18 & 0,64 & 0,40 \\
Médias $\pm \mathrm{DP}$ & $0,52 \pm 0,12$ & $0,39 \pm 0,08$ \\
\hline
\end{tabular}

Por se tratar de um marcador endógeno de diluição, a ureia tem como vantagem o fato de não ser necessária administração de nenhuma molécula, o que torna a técnica mais simples e menos invasiva. Além disso, a ureia apresenta-se como bom marcador de diluição por não ser consumida ou produzida pelas células pulmonares (HASLAM et al., 1999). Outra vantagem é que as concentrações de ureia no plasma e, portanto, no FEP são relativamente altas. Dessa forma, mesmo após a diluição pelo LBA, é tecnicamente simples medir a sua concentração no lavado recuperado (RENNARD et al., 1986).

\section{CONCLUSÕES}

A metodologia desenvolvida utilizando o kit ureia UV LabTest ${ }^{\circledR}$ é uma alternativa acessível para utilização em equipamentos de baixo custo e de fácil execução e permite obter resultados semelhantes aos já previamente estabelecidos para a espécie equina. Portanto pode ser empregada tanto na rotina quanto na pesquisa clínica para estimar o volume de FEP e, a partir disso, calcular a concentração ou atividade real de componentes que se deseja investigar neste fluido.

\section{REFERÊNCIAS}

ADAMS, F. H.; MOSS, A. J.; FAGAN, L. The tracheal fluid in the fetal lamb. Biological Neonatology, v. 5, n. 4, p. 151-158, 1963.

BAUGHMAN, R. P.; BASKEN, C. H.; LOUDON, R. G.; HURTUBISE, P.; WESSELER, T. Quantification of bronchoalveolar lavage with methylene blue. American Review of respiratory disease, v. 128 , n. 2, p. 266-270, 1983.

DARGAVILLE, P. A.; SOUTH, M.; VERVAART, P.; MCDOUGALL, P. N. Validity of markers of dilution in small volume lung lavage. American Journal of Respiratory Critical Care Medicine, v. 160, n. 3, p. 778-784, 1999.

EFFROS, R. M.; MURPHY, C.; OZKER, K.; HACKER, A. Kinetics of urea exchange in air-filled and fluid filled rat lungs. American Journal of Physiology, v. 263, n. 6, p. 1619-1626, 1992.

FERNANDES, W. R.; YONEZAWA, L. A.; MIRANDOLA, R. M. S.; MORI, E.; LESSA, D. A. B.; ABRAMOVITC, G. Serum and alveolar immunoglobulin levels in healthy, infected with EVH-1 and with IAD horses. In: CONGRESS OF THE WORLD EQUINE VETERINARY ASSOCIATION, 8., 2003, Buenos Aires. Proceedings... Buenos Aires, 2003. v. 1, p. 137-137.

HASLAM, P. L.; BAUGHMAN, R. P. Guidelines for measurement of acellular components and standardization of BAL. European Respiratory Journal, v. 14, p. 245-248, 1999.

HENNIG-PAUKA, J.; GANTER, M.; GERLACH, G. F.; ROTHKITTER, H. J. Enzyme activities, protein content and cellular variables in the pulmonary epithelial lining fluid in selected healthy. Journal of Veterinary Medicine Series a Physiology Pathology Clinical Medicine, v. 48, n. 10, p. 631-639, 2001.

HOFFMAN, A. M.; VIEL, L. Techniques for sampling the respiratory tract of horses. Veterinary Clinics of North American: Equine Practice. v. 13, n. 3, p. 463-475, 1997.

KIRSCHVINK, N.; FIEVEZ, L.; DOGNÉ, S.; BUREAU, F.; ART, T.; LEKEUX, P. Comparison of inulin with urea as dilutional markers of bronchoalveolar lavage in healthy and heaves-affected horses. Veterinary Research, v. 32, p. 145-154, 2001. 
MARCY, T. W.; MERRILL, W. W.; RANKIN, J. A.; REYNOLDS, H. Y. Limitations of using urea to quantify epithelial lining fluid recovered by bronchoalveolar lavage. American Journal of Respiratory Research, v. 135, n. 6, p. 1276-1280, 1987.

MILLS, P. C.; LITSTER, A. Using urea dilution to standardize cellular and non cellular components of pleural and bronchoalveolar lavage (BAL) fluids in the cat. Journal of Feline Medicine and Surgery, v. 8, n. 2, p. 105-110. 2006.

MILLS, PC.; LITSTER, A. Using urea dilution to standardise components of pleural and bronchoalveolar lavage fluids in the dog. The New Zealand Veterinary Journal, v. 53, n. 6, p. 423-428. 2005.

McGORUM, B. C.; DIXON, P. M.; HALLIWELL, R. E. W.; IRVING, P. Evaluation of urea and albumen as endogenous markers of dilution of equine bronchoalveolar lavage fluid. Research in Veterinary Science, v. 55, n. 1, p. 57-59, 1993.

MCKANE, S. A.; SLOCOMBE, R. F. Sequential changes in bronchoalveolar cytology after autologous blood inoculation. Equine Veterinary Journal, Supplement. v. 30, p. 126-130, 1999.
RENNARD, S. I.; BASSET, G.; LECOSSIER, D.; O’DONNEL, K. M.; PINKSTON, P.; MARTIN, P. G.; CRYSTAL, R. G. Estimation of volume of epithelial lining fluid recovered by lavage using urea as marker of dilution. Journal of Applied Physiology, v. 60, n. 2, p. 532-538, 1986.

ROBINSON, N. E. International Workshop on Equine Chronic Airway Disease. Michigan State University. Equine Veterinary Journal, v. 33, n. 1, p. 5-19, 2001.

STRANG, L. B. The pulmonary circulation and intersticial space. Chicago: IL. Univ. of Chicago Press, 1968.120 p.

WARD, C.; DUDDRIDGE, M.; FENWICK, J.; WILLIAMS, S.; GARDINER, P. V.; HENDRICK, D. J.; WALTERS, H. The origin of water and urea sampled at bronchoalveolar lavage in asthmatic and control subjects. American Journal of Respiratory Research, v. 46, n. 2, p. 444-447, 1992.

Protocolado em: $1^{\circ}$ dez. 2008. Aceito em: 22 dez. 2009. 